\title{
State Assessment Score Reporting Practices for English Learner Parents
}

\author{
Joseph A. Rios \& Samuel D. Ihlenfeldt \\ University of Minnesota
}

\begin{abstract}
Author's Note
Joseph A. Rios: https://orcid.org/0000-0002-1004-9946

Samuel D. Ihlenfeldt: https://orcid.org/0000-0003-3642-8407

Both authors hold departmental affiliation at the Department of Educational Psychology, University of Minnesota, Twin Cities.
\end{abstract}

The first author would like to thank See Xiong for inspiring this study. Her story of being a child responsible for navigating the education system with refugee parents unfamiliar with the language and policies of the country is common amongst millions of students in the United States. This study is our effort to assist in building more equitable assessment resources for all individuals in our nation.

Author contribution statement: The first author conceived of the presented idea, while the second author identified all data sources and conducted the variable coding. All authors interpreted findings, drafted the article, and conducted critical revisions of the article throughout the review process. Final approval of the version to be published was made by all authors.

Correspondence concerning this article should be sent to Joseph A. Rios, University of Minnesota, 56 E. River Road, 164 Education Sciences Building, Minneapolis, MN 55455. Email: jrios@umn.edu

Cite as:

Rios, J. A., \& *Ihlenfeldt, S. (2021). State assessment score reporting practices for limited English proficient parents. Educational Measurement: Issues and Practice. Advanced online publication. doi: $10.1111 /$ emip.12424 


\begin{abstract}
This study sought to investigate how states communicate results for academic achievement and English language proficiency (ELP) assessments to parents who are English learners (EL). This objective was addressed by evaluating: (a) whether score reports and interpretive guides for state academic achievement and ELP assessments in each state were translated for EL parents; and (b) if so, whether recommended score reporting guidelines were followed in practice. Results demonstrated that for state achievement tests, 29 states had translated score reports and 28 had translated interpretive guides. Nearly every state translated these materials for their ELP assessments in a wide variety of languages. Across ELP and state achievement assessments, most states were found to limit statistical jargon, utilize figures/graphics to communicate test results, and include follow-up information for parents. However, states rarely provided personalization, statements on intended score use, a student's score history, or a direct link to their interpretive guide in their score reports. Improvements in a number of areas were observed from prior reviews. Recommendations on making score reports and interpretive guides more accessible and interpretable for EL parents are discussed.
\end{abstract}

Keywords: score reporting, parents, linguistic minorities, English learners, state testing programs 


\section{State Assessment Score Reporting Practices for English Learner Parents}

Within the U.S. public education system, there has been an increase in the proportion of students who come from non-English-speaking homes and backgrounds. ${ }^{1}$ As an example, recent estimates suggest that 8.06 million students (approximately $16.7 \%$ of all students in the U.S.) have at least one parent who is not fluent in English (hereon referred to as EL parents; further description of this population is provided in the following paragraph; EdWeek, 2019;

McQuiggan et al., 2017). Approximately five million of these students, who are referred to as English learners (ELs), receive specialized or modified instruction in the English language, and account for $10 \%$ of the total U.S. student population (USDOE, n.d.). Although $73 \%$ of all ELs speak Spanish as a first language, there are more than 350 native languages represented in U.S. public schools (U.S. Census Bureau, 2015). Due in part to language, ELs have consistently faced more academic challenges than their native English-speaking counterparts, with only $63 \%$ graduating from high school (the national average is $82 \%$; Sanchez, 2017). ${ }^{2}$ To improve this achievement gap, the U.S. federal government has implemented policies that prioritize the assessment and reporting of EL performance on measures of English language proficiency and content knowledge.

The focus of this study is on EL parents, many of whom do not read, speak or write fluently in English. It should be noted that EL parents vary in home language, education, immigration status, and the EL status of their children. ${ }^{3}$ This paper does not focus on the smaller

\footnotetext{
${ }^{1}$ According to the Census Bureau's 2016 American Community Survey, 72\% of public-school students aged 5 to 17 who report speaking English "less than very well" were born in the United States compared to 28\% who were foreign born (Bialik et al., 2018).

${ }^{2}$ Beyond linguistic challenges, ELs tend to be homeless, migrant, served by Title I schools, and classified as possessing learning disabilities at higher rates than the general student population (USDOE, n.d.).

${ }^{3}$ The publicly available American Community Survey data from which the prior statistics were created does not provide an EL parent subgroup analysis.
} 
subset of parents who are not ELs with students who are. With that in mind, although the findings/recommendations in this paper are designed to advise score reporting practices for EL parents, many conclusions may also be beneficial to improving the visual (e.g., creating simpler designs) and linguistic (i.e., improving the interpretability of language for the intended audience) accessibility of score reports for parents outside this focal group.

\section{Federal Policies on Providing Linguistically Accessible Score Reports for EL Parents}

While score reporting is important because it allows parents to learn about their child's strengths and weaknesses, prior research has shown that parents will not engage with a score report if they feel that their English language proficiency is not sufficient to do so or if they are unable to interpret the results (Kim et al., 2016). This finding suggests that to effectively communicate assessment results to EL parents, information must be linguistically accessible.

To address this concern, section $\S 1111(\mathrm{~b})(2)(\mathrm{B})(\mathrm{x})$ of the Every Student Succeeds Act (ESSA; 2015) requires states to provide student assessment result information to parents in their native language, to the extent practicable. A failure to provide such accessibility would exclude EL parents from receiving the same information and materials as English-speaking parents due to their language status. As noted by Faulkner-Bond et al. (2013), this exclusionary practice can be interpreted as a violation of individuals' civil rights based on Title VI of the Civil Rights Act of 1964. This act stipulates that no person in the United States should be denied the same benefits as others from institutions receiving federal aid, such as schools, based on their race or national origin (federal courts have established that language is a proxy for the latter; see Zuckerman, 2010).

Clearly, providing linguistically accessible score reports to EL parents is an important first step in communicating information about their child's assessment results; however, 
language is only one of many factors that may influence the interpretability of such information. In the sections that follow, we discuss prior research on outlining best practice guidelines for reporting scores to parents, summarize the literature on state score reporting practices, and provide the rationales and objectives for the current study.

\section{Score Reporting Recommendations from Parents}

To date, there has been limited research investigating how best to communicate assessment results to parents in general, let alone those that are ELs. The research efforts in this area have relied on conducting parent focus groups to ascertain how states can increase interpretability when reporting assessment results. From these studies, a number of trends can be summarized.

First, parents like to know the purpose and content of the assessment itself as well as the consequences associated with the test results (Kim et al., 2016). Second, the first piece of information that they would like to see is their child's overall performance and whether their child met proficiency (Kannan et al., 2018). To do so, Miller and Watkins (2010) showed that communicating scores via graphical representations can assist parents' comprehension. Third, although both criterion- and norm-referenced scores are viewed as important (A-Plus Communications, 1999), parents generally prefer the latter, with particular interest in comparative information in relation to the school average (Kannan et al., 2018; Kim et al., 2016; Zapata-Rivera et al., 2014). Fourth, as parents desire information on how to help their child improve their performance (Zapata-Rivera et al., 2014), they tend to pay more attention to subscores than composite scores (Kim et al., 2016). Fifth, although parents view interpretive guide information as potentially useful, they do not want the guide itself to be too lengthy (Kim et al., 2016). 
Finally, interpretability of assessment results may differ based on parental educationlevel and English language proficiency (Kannan et al., 2018; Miller \& Watkins, 2010; ZapataRivera et al., 2014). In regard to EL parents, research conducted by Zapata-Rivera et al. (2014) suggests that they would like to see example questions in their native language and have a rollover vocabulary feature that translates English terms into their native language when a score report and interpretive guide is not provided in that language.

\section{Score Reporting to Parents in Practice}

To evaluate whether the recommendations noted above have been followed in practice, a handful of studies have investigated how state testing programs report scores to parents. One of the earliest studies was conducted by Barber et al. (1992) who surveyed 50 assessment directors across the U.S. in 1987. Of the 41 states represented in the survey, only 13 required that test scores should be sent to parents. Of these 13, none mandated that parents should receive either information on how their child performed relative to previous tests, or strategies for helping their children perform better.

In an updated study, Goodman and Hambleton (2004) conducted an analysis of individual-level score reports and interpretive guides developed to communicate state academic achievement assessment performance for parents and guardians. Of the 11 U.S. states surveyed, all were found to provide parents with a score report and some form of an interpretive guide, and most states reported assessment results in relation to both state-defined performance levels and subdomains. However, a number of areas for improvement were noted, which included a need to provide information regarding measurement error, reduce statistical jargon (e.g., terms such as standard error), and increase interpretive information for test users (e.g., defining critical performance levels). 
The most recent analysis conducted by Faulkner-Bond et al. (2013) focused on parental score reporting practices for ELP assessments across the U.S. Overall, the authors found that while most states provided parents with score reports, many did not provide estimates of measurement error, information on progress or "growth" in relation to prior test performance, or advice on how students could improve their performance. Most states were found to make interpretive information available to parents; however, many of the guides were developed for specific use by teachers, administrators, and policy makers. Finally, considering that many EL parents are expected to be nonnative English users themselves, the authors evaluated whether states translated score reports and/or interpretive guides. They found that translated materials, particularly for interpretive guides, were rare. Overall, these studies suggest that although there have been advancements in reporting assessment results to parents, particularly EL parents, many areas of improvement still need to be addressed.

\section{Study Rationale and Objective}

To promote parents' involvement in their EL children's learning, it is imperative that states effectively communicate assessment results concerning ELP and academic content proficiency that can be understood by those parents. However, the most recent surveys of score reporting practices were conducted before the passage of ESSA, and thus, may not reflect current federal policies nor changes to testing programs. Second, research has rarely focused on communication efforts specifically for parents. To date, the only national review of score reporting practices that has considered this area was Faulkner-Bond et al. (2013); however, their primary focus was on ELP assessments. Thus, there has not been a study on score reporting practices for EL parents on state academic achievement tests nor an updated study for ELP assessments in nearly a decade. 
To address these limitations, the objective of this study is two-fold. First, we evaluate the availability of linguistically accessible score reports and interpretive guides for state academic achievement and ELP assessments for EL parents. Second, for those resources that are translated for EL parents, we look to investigate whether recommended score reporting guidelines are followed in practice. These study objectives are addressed via the following research questions:

1. Are score reports and interpretive guides provided (i.e., translated) in a language that EL parents can understand?

2. For those reports that are accessible for EL parents, do states follow best practice guidelines to support parents' comprehension of their child's performance?

The findings from this study have the potential to inform practitioners about areas of need for improving score reporting practices for EL parents.

\section{Method}

The sections that follow describe the data collection, variable coding, and interrater agreement processes of our systematic review.

\section{Data Collection}

For all 50 states and the District of Columbia, we sought to collect the score report template, interpretive guide, and linguistic accommodations made available to EL parents. ${ }^{4}$ This was done by visiting each state education agency's (SEA) website to: (a) identify the academic achievement and ELP testing program that the state engaged in; (b) determine if parental score reports and interpretive guides were distinct from other states'; and (c) if so, obtain the information noted above. If these documents could not be located by searching the agency's website, a Google search was conducted. In cases where these documents were not made

\footnotetext{
${ }^{4}$ Although there were states that participated in a testing consortium (e.g., Smarter Balanced Assessment Consortium [SBAC], WIDA Consortium), results were disaggregated for each state.
} 
available online, contact information for state assessment directors was acquired, either via the SEA website or by contacting the SEA's helpline. State assessment directors or related personnel were then directly emailed to request the missing documents (an example email is reproduced in Appendix A of the online supplementary document). If neither source responded or stated that the document requested was unavailable, data were coded as missing. A total of 34 states were contacted regarding academic achievement score reports and guides, of which 29 responded. For EL assessments, 12 states were contacted and 10 responded. This data collection was completed between June 1 and July 1, 2020.

\section{Variable Coding}

To examine score reporting practices, we relied on prior studies to guide our variable coding (e.g., A-Plus Communications, 1991; Faulkner-Bond et al., 2013; Goodman \& Hambleton, 2004; Hambleton \& Zenisky, 2013; Kannan et al., 2018; National Education Goals Panel [NEGP], 1998; Roduta Roberts \& Gotch, 2019; Zapata-Rivera et al., 2014). For each assessment type (state academic achievement and ELP tests), variable coding was conducted separately for score reports and interpretive guides. The coding process consisted of first engaging in coder training, which involved both authors coding three testing programs together. During the training set, the first and second author carefully discussed any inconsistencies in their ratings, upon which certain variables (e.g., intended use; described below) were further operationalized. After completing this training, the second author coded all remaining testing programs, while the first author coded a $20 \%$ overlap for interrater reliability.

\section{Score Report Variables}


Variables coded for score reports fell into the following categories: (a) linguistic; (b) layout; (c) intended use; (d) test performance; (e) statistical jargon; and (f) supplementary information variables.

Linguistic Variables. First, we coded for whether a score report was made available, and if so, the availability of translations for EL parents. If a translation was made available, we coded for the languages provided. If no translation was made available, we examined whether linguistic accommodations were offered (e.g., mouseovers). If neither were presented, all further coding was stopped, as the contents of a score report were coded as inaccessible to EL parents.

Layout Variables. Several variables related to the layout of the score report were included, which were drawn from Faulkner-Bond et al. (2013) and Goodman and Hambleton (2004). Specifically, we coded for: (a) score report length; (b) whether score reports contained graphics; (c) if so, whether there was supporting text to aid in the understanding of those graphics; (d) the incorporation of color into the score report; and (e) availability of a HTML link to sample test items.

Intended Use Variables. Based on the recommendations of Roduta Roberts and Gotch (2019), we coded for whether score reports contained: (a) a title clearly identifying what the report was for; as well as statements on (b) assessment purpose; (c) intended use of the assessment results; and (d) the knowledge and skills measured by the assessment.

Test Performance Variables. The largest category of variables was associated with the communication of test performance. This consisted of whether the following were provided: (a) a snapshot or summary of performance; (b) raw scores; (c) scale scores; (d) criterion-related information; (e) norm-referenced information; and (f) self-referential information (i.e., progress or growth scores). Further, for raw and scale scores, we also evaluated whether testing programs 
provided the full score range and confidence intervals or errors bands. If criterion-related information was provided, we examined if performance categories were defined, while if normative and self-referential feedback were offered, the level of comparisons to others (class, school, district, state, nation) and past performance (e.g., growth percentiles, previous year's test scores, other representation of "progress"), were respectively coded.

Statistical Jargon Variables. Building off the work of Kannan et al. (2018), the inclusion of statistical jargon was evaluated by dichotomously coding for the presence of any of the following terms: mean/average, median, mode, standard error, percentile, quartile, subscore, error band, and reliability. Furthermore, if any of these terms were employed, we examined if a description or definition was provided on the score report.

Supplementary Information Variables. Based on the research of Roduta Roberts and Gotch (2019), the presence of supplementary information on score reports was investigated. Specifically, we were interested in knowing: (a) whether test results were linked to possible follow-up activities for improving learning; and (b) the availability of contact information for parents with questions about their child's performance. Lastly, we coded for whether a translated parent website with test resources was available.

\section{Interpretive Guide Variables}

Some states differentiated between parent guides and interpretive guides, typically designing the interpretive guides for other assessment stakeholders such as teachers and school administrators. For this study, we first looked for a parent guide as the primary focus of this research is on parental accessibility. If that was not available, we then looked for interpretive materials that were generally designed for non-parental educational stakeholders (e.g., teachers), 
but were made accessible to parents. Variables coded for interpretive guides fell into two categories: (a) linguistic; and (b) interpretive information variables.

Linguistic Variables. Similar to score reports, we were interested in knowing: (a) whether an interpretive guide was available to parents; (b) if so, the mode of delivery; (c) and the targeted audience (parents, teachers, administrators, all of the above). If an interpretive guide was accessible to parents, we next coded for the presence of translated versions (and if available, the language translated), and if not present, the inclusion of linguistic accommodations to assist EL parents' access to the content. Further coding of interpretive guide content was ceased when it was determined that neither translations nor linguistic accommodations were available.

Interpretive Information Variables. To understand the contents of interpretive guides, the presence of the following descriptions/inclusions were coded for: (a) performance level descriptors; (b) scoring rubrics; (c) possible uses or interpretations of scores; (d) common misuses or misinterpretations of scores; (e) example questions; and (f) definitions of any jargon included on the associated score report. In addition, as parents have noted a preference for shorter interpretive guides (Kim et al., 2016), we coded the page length of each testing program's document.

\section{Interrater Reliability}

Interrater agreement of variable coding was evaluated between authors for $20 \%$ of state academic achievement and ELP testing programs. Cohen's kappa and percent agreement were calculated separately for the 142 coded variables included in our study using the R package irr (Gamer et al., 2012). Adequate interrater agreement was established based on obtaining Cohen's kappa and percent agreement values of .80 and 80\%, respectively (Landis \& Koch, 1977). 
Across variables, the median kappa value between the two raters was $.76^{5}$, while percent agreement was $93.96 \%$. Any disagreements were resolved through consensus prior to conducting the final analysis.

\section{Results}

Results are presented first for academic achievement followed by ELP assessments (Table 1).

\section{State Academic Achievement Assessments}

Sample state academic achievement assessment score reports were available for 49 states $^{6}$ and the District of Columbia. ${ }^{7}$ Many of these states belonged to test consortia that shared the same assessment (but not necessarily the same score report), such as Partnership for Assessment of Readiness for College and Careers $(n=3$; PARCC) or Smarter Balanced Assessment Consortium ( $\mathrm{n}=20$; SBAC). Additionally, many states used assessments developed by Pearson $(\mathrm{n}=19) .{ }^{8}$ Of the 50 available states, 29 provided translated score reports and 28 had translated interpretive guides. Eight states provided only a translated interpretive guide but were nonetheless included in the score report analysis as they translated the English score report template. A total of $38 \%$ had both a translated score report and a translated interpretive guide. Below we present score report and interpretive guide variables separately.

\section{Score Reports}

\footnotetext{
${ }^{5}$ We observe that one possible issue in reporting kappa is how it handles variables with $100 \%$ agreement, and no variation in the results (for instance, both coders rate that $100 \%$ of score reports have a certain feature). In these cases, kappa cannot be calculated. This was the case for 58 variables.

${ }^{6}$ Alabama was the exception, as they are in the process of developing a new state assessment, and example score reports for their most recent assessment are not yet available to the public.

${ }^{7}$ For the remainder of the analysis, when we refer to "state" it includes the District of Columbia.

${ }^{8}$ Other companies such as the Data Recognition Corporation and Riverside Insights produced large-scale assessments, but how many states employed these assessments is not publicly available.
} 
With the exception of the language subsection that follows this paragraph, the presented score report analyses included score reports that were not translated from English, but had a translated interpretive guide (the guide included a translation of the English score report template). The assumption is made that translated score report templates effectively communicate information on the score report to EL parents.

Language. The 29 translated score reports were available in 26 total languages. On average, each state with translated materials offered score reports in 3.9 non-English languages $(\mathrm{SD}=4.04)$, although many states only offered a single language of translation beyond English $(n=13)$. Of those states providing more than one language, four translated score reports in 10 languages or more: Massachusetts $(n=16)$, Illinois $(n=10)$, Rhode Island $(n=10)$, and Texas $(n$ $=10)$. Across states, Spanish was the most commonly provided non-English language $(\mathrm{n}=28$ states), followed by Chinese $(n=11)$, Vietnamese $(n=10)$, and Arabic $(n=9)$. Of the 23 states that did not have a translated guide, no other linguistic accommodation or aids appeared to be offered. Going forward, the following analyses will look at all 37 states that had either a translated score report or a translated interpretive guide that included a translated English language score report template.

Intended Use. Most of the 37 coded score reports contained a statement about the assessment's purpose $(\mathrm{n}=26)$, and many of those gave a description of the knowledge and skills measured by the assessment $(\mathrm{n}=32)$. Further, every score report was broken down by subdomain, but not all described what the subdomains consisted of beyond a title $(n=25)$. As for the intended use of the assessment, less than half of the score reports $(n=18)$ stated how scores would be utilized for students (e.g., student placement, academic decision-making, or informing intervention programs). 
Layout. A single snapshot score (i.e., a scale, criterion, or norm-referenced score summarizing a student's performance on the assessment), was present on every report. Most of the score reports $(n=32)$ referred to the student as "your child", "your student", or referenced parents, guardians, or families. Only 23 score reports were personalized, with even fewer referencing the student by name in the body of text of the score report $(n=13)$. In terms of data visualization, almost every state made use of color $(\mathrm{n}=36)$ and graphics (defined as any nontextual depiction of a score, not necessarily a graph; $n=37$ ). Most of those containing graphics also contained text to aid interpretation of visualizations $(\mathrm{n}=33)$. When looking at a combination of math and ELA state assessments, the average score report was 3.3 pages long $(S D=1.24)$

Test Performance. The most common indicators of a student's overall performance were a scaled score $(n=37)$ and a criterion score $(n=37)$. For most states, the criteria were defined beyond name alone - either numerically $(n=36)$ or descriptively $(n=33)$. Other indicators of student performance included raw scores $(n=3)$, and norm-referenced scores to the school $(\mathrm{n}=$ $27)$, district $(\mathrm{n}=26)$, and state $(\mathrm{n}=30)$. Twenty-one states also had a self-referenced score history, the most common was a comparison of criterion scores over time $(n=15)$. For scaled scores, it was typical for states to define the full score range $(n=34)$, and less common for them to give error bands around that score $(n=20)$.

While every state included subdomain scores, there was some variance in how they were presented. Similar to the overall score, criterion scores were very common $(n=29)$ for reporting subdomain results. Unlike the overall score, it was far less common for these criteria to be defined either numerically $(\mathrm{n}=2)$ or descriptively $(\mathrm{n}=18)$. In addition, some states provided the raw score $(n=14)$, scaled score $(n=4)$, or a norm-referenced score $(n=4)$ for each subdomain. 
Jargon Usage. In general, little statistical jargon was found throughout the translated score reports. The terms "mean" and "average" were the most common $(n=22)$, but also the least explained when used $(n=1)$. Other terms, such as "percentile" $(n=12)$ and "standard error" $(n=7)$ also appeared, but far less frequently. That said, when used, they were much more likely to be explained either in the score report or the associated guide $(n=12$ and 7 , respectively). The following terms never appeared across the sample: "median", "mode”, "quartile", "confidence interval", or "reliability".

Follow-up Information. If a parent was interested in determining how to utilize obtained test score information, most states $(n=23)$ offered them some guidance. These supports included: (a) tasks students could complete to better themselves in a domain; (b) links to websites with learning activities; (c) practice tests; (d) guides to talking to your child about their test scores; (e) guides to parent teacher conferences; (f) links to more in depth information about proficiency levels and test construction. In addition, some states $(n=19)$ described who the parent might contact if they had questions regarding either scores on the report, or the score report itself, such as their child's teacher $(n=14)$, school $(n=6)$, principal $(n=3)$, or district $(n$ $=3$ ). About half of the states with translated score reports also had translated websites with resources regarding the assessment $(n=18) .{ }^{9}$

\section{Interpretive Guides}

Like score reports, most states had some interpretive materials $(n=46)$, but only 28 offered these materials in a language other than English. Of the 28 states with translated

\footnotetext{
${ }^{9}$ The most common method of translation for parent websites was embedding a Google translate HTML widget directly on the page, meaning that resource pages could be translated into many more languages than were available on the score report itself.
} 
interpretive guides, nine belonged to states that did not offer translated score reports. This section will look at each of the 28 states with translated guides.

Language. A total of 27 distinct languages were found across all 28 guides. On average, each state had 3.7 languages available $(\mathrm{SD}=3.7)$. The trends in interpretive guides closely mirrored those of score reports, with Spanish as the most common translated language $(n=27)$, followed by Arabic $(n=11)$, Chinese $(n=10)$, and Vietnamese $(n=9)$. The states offering the most translations were Ohio $(n=11)$, Texas $(n=10)$, Minnesota $(n=10)$, and Illinois $(n=10)$. No other linguistic accommodations or supports were found in the non-translated interpretive materials.

Layout. Translated interpretive guides were either a stand-alone document $(\mathrm{n}=21)$, included as part of the original score report $(n=2)$, or hosted online $(n=5)$. Excluding websites, interpretive guides tended to be longer than score reports, at 5.52 pages on average $(S D=5.86)$. In general, these guides were designed specifically for parents $(n=24)$, but it was unclear how parents could locate them as it was uncommon for states to provide a link directly to the guide from the score report $(n=9)$.

Interpretive Information. It was typical for interpretive guides to describe the intended use of the test score $(n=21)$. Less common was describing the knowledge and skills required for the assessment $(n=13)$, but in the case when it was not included in the guide, it was often already included on the score report itself $(n=12)$. Several guides also noted that the scores ought not to be used as the sole indicator of a student's academic abilities $(n=4)$. Only four guides contained performance level descriptors, one described a scoring rubric, and four included sample test items. 
Follow-up Information. Like score reports, some of the interpretive guides had followup information for parents seeking resources on how to improve their student's performance. Specifically, a total of 11 guides offered suggestions for steps to take to help students improve, and 11 had information on who to contact with more information regarding the score report.

\section{ELP Assessments}

A total of 11 distinct ELP programs were identified based on unique score report and interpretive guide combinations. The most represented, WIDA, had 35 states and the District of Columbia as members. Overall, all 11 ELP testing programs provided translated score reports, while seven had translated interpretive guides. Going forward, the analysis will be done at the state level, similar to the work of Faulkner-Bond et al. (2013). ${ }^{10}$

\section{Score Reports}

Language. A large variety of translation options were offered for ELP assessments - on average, programs provided reports in 35.08 languages $(\mathrm{SD}=18.16)$. That said, the majority of translations were offered by WIDA states $(n=46)$ and Ohio $(n=32)$. Every state had Spanish as a translation option, followed by Arabic, Chinese, and Vietnamese (all with $n=45$ ). Of the 46 languages offered by WIDA, 18 did not appear for any other testing program.

Intended Use. A statement on the purpose of the assessment was present on most reports $(n=42)$, but very few contained a statement on how the scores would be used $(n=3)$. Like the state academic achievement reports, most of the ELP reports described the knowledge and skills necessary to succeed on the assessment $(n=46)$, but none linked directly to an example of what assessment items might look like. Every score report was broken down into subdomains $(\mathrm{n}=51)$,

\footnotetext{
${ }^{10} \mathrm{We}$ acknowledge that programs such as WIDA may disproportionately influence the results, but this should give a fuller picture of trends nationwide and aligns with previous research on the topic.
} 
with most testing programs describing the knowledge and skills that comprised each subdomain $(\mathrm{n}=46)$.

Layout. A score snapshot was available on 13 reports in the form of a criterion score. Notably, WIDA did not offer a single snapshot, but instead displayed color-coded scores on all four of their subdomains. Beyond the snapshot, most score reports made use of graphics to display a student's performance $(n=45)$, with 44 of those having supporting text to aid score interpretation. All but one of the score reports made use of color in some capacity. The length of ELP score reports was consistent: they were mostly one-page $(n=47)$ or two-pages long $(n=4$; $M=1.08, S D=0.27)$. In comparison to state achievement reports, ELP score reports were much less personalized. Specifically, almost no states had any personalization $(n=4)$, and of those that did, only half referred to the student by name in text beyond the headers. Additionally, ELP score reports were much less likely to have language indicating that the score report was to be read by parents, such as directing the report to the parent, guardian or family of the student $(\mathrm{n}=$ 5).

Test Performance. An overall criterion score was reported in each program, and in some cases the criterion levels were defined numerically $(n=40)$, and in far fewer cases, descriptively $(n=15)$. Most assessments also reported a scale score $(n=47)$, although fewer described the scale score range $(n=40)$ or provided a confidence interval $(n=42)$. A minority reported normreferenced scores to the state and district $(n=7)$, and even less reported on a student's score history $(n=2)$.

On every score report $(n=51)$, the overall score was broken down into four subdomains: listening, speaking, reading, and writing. In most cases, these subdomain scores were presented as a criterion score $(n=50)$ and a scaled score $(n=48)$. Subdomain criterion scores were 
typically defined numerically $(n=40)$, and much less frequently, descriptively $(n=15)$. Two reports also contained self-referenced criterion scores showing a student's ELP history, while none contained norm-referenced subdomain scores.

Jargon Usage. Very little statistical jargon was employed on the ELP score reports. The term "confidence interval" appeared on the WIDA score report, meaning 36 states included the term and described it in their interpretive guide. The terms "mean" or "average" were used seven times, "standard error" five times, and "percentile" once. None of the other coded terms ("median", "mode", “quartile", “subscore", and "reliability”) appeared on the sampled score reports. Of the terms that did appear, only "mean" or "average" were not defined in either the score report or supporting guide.

Follow-up Information. Guidance on who parents could contact with questions could be found on five score reports. Additionally, five score reports provided activities and practice tasks for students to improve their performance. Lastly, most of the programs had a parent resource website that was available in more than one language $(n=42)$.

\section{Interpretive Guides}

Nearly every ELP program had an interpretive guide $(n=49)$, and of those, 42 were published in languages other than English.

Language. Translated interpretive guides were made available in 16 languages, with each program having an average of 10.76 translated versions $(S D=3.27)$. Every program that offered a translation provided guide information in Spanish, while four languages (Bengali, Khmer, Korean, and Punjabi) were only offered by one state. One program, WIDA, offered the most translations (12 languages); three states only had Spanish available. For states without translations, no other linguistic accommodations or supports were offered. 
Layout. The interpretive guides were mostly stand-alone documents $(n=40)$, although one was directly attached to the score report, and one was a website (which was linked to directly from the score report). The average length for translated interpretive guides was 1.98 pages long $(S D=0.42)$, with most of the guides only 1-page in length $(\mathrm{n}=36)$. For the most part, these guides were developed specifically with parents in mind $(n=41)$, although as with state score reports, only two included a direct link to the guides, which may have potentially limited their accessibility.

Interpretive Information. These interpretive guides offered little guidance on information not included on the score reports - only one interpretive guide described the knowledge and skills necessary to succeed on the assessment. Most of the translated guides described the intended use of the test score $(n=40)$, but none described possible test score misuses. Sample test items were not included in any of the interpretive guides.

Follow-up Information. Activities designed to help a student improve and information on who to contact with follow-up questions were each described on forty reports.

\section{Discussion}

This study sought to investigate how states communicate academic achievement assessment results of academic knowledge and ELP to EL parents. From our review, a number of key trends were observed. Below we separate these trends by successful practices and areas in need of future improvement.

\section{Successful Practices}

One of the most important contributions of this study was documenting the prevalence of translated materials across state ELP and academic achievement assessments. Our findings noted a 70\% increase from 2012 in the number of states that had translated score reports and 
interpretive guides for their ELP assessment (i.e., translated materials are available in almost every state; Faulkner-Bond et al., 2013). Although we do not have comparative information for academic achievement assessments, nearly three-quarters of states had translated materials for this assessment type. In addition, we found that states made a concerted effort to increase accessibility to a broad linguistic audience, with the average state offering their materials in 35 different languages for their ELP score reports (WIDA provided score reports in 46 different languages). However, most state education agencies catered to Spanish speakers, the largest EL group in the United States (Spanish score reports and interpretive guides were made available for $97 \%$ of the 37 state academic achievement assessments and $100 \%$ of the 51 state ELP assessments with translated materials).

For those states that translated their materials, a number of positive trends were observed in score report and/or interpretive guide designs. For instance, besides the terms "mean" and "average", we observed minimal use of statistical jargon, following prior recommendations (e.g., Goodman \& Hambleton, 2004). Concerning the reporting of scores, most states followed the recommendation that key findings should be highlighted by utilizing both charts and/or graphics (e.g., Zenisky \& Hambleton, 2012). For instance, $100 \%$ and $88 \%$ of translated academic achievement and ELP reports contained graphics, respectively, which most often came in the form of a score snapshot that clearly provided a summary of results to parents. To increase interpretability of the graphics/scores, many state and ELP score reports contained either a text or graphic description and definition of measurement error $(20 / 37,54.1 \% ; 42 / 51,82.4 \%$, respectively), which has been recommended by prior researchers (e.g., Roduta Roberts \& Gotch, 2019). 
Finally, to assist parents in helping their children improve test performance, it has been advocated that follow-up guidelines should be made available (e.g., NEGP, 1998). We found that this information was present on the majority of state assessment score reports $(23 / 37 ; 62.2 \%)$, and while it did not appear on as many of the ELP score reports, it was available on numerous interpretive guides $(40 / 49 ; 81.6 \%)$. Furthermore, many of the state assessment score reports $(19 / 37 ; 51.4 \%)$ and the majority of ELP interpretive guides $(40 / 51 ; 78.4 \%)$ provided parents with information on who they could contact should they have any questions regarding their child's test scores. Taken together, these results suggest that states are following many recommended practices for improving clarity and interpretability of assessment results for parents. However, in saying that, we also documented a number of areas in need of future improvement.

\section{Areas in Need for Future Improvement}

As noted earlier, most states did have translations for score reports and interpretive guides for their assessments of academic content knowledge, but in many cases those translations were limited exclusively to Spanish, and to a lesser extent Chinese, Vietnamese, and Arabic. Although these four languages represent the native language for $81.2 \%$ of the U.S. EL student population (National Center for Education Statistics, 2020), approximately one million students come from a home in which the language spoken is not one of these four. As a result, there is a need to improve accessibility for these disparate language groups on this assessment type. Further, translated interpretive guides were found to be both far less available than translated score reports and offered in fewer languages. Thus, greater efforts should be made to improve accessibility of these materials, as they can assist in improving interpretability of scores for parents. 
Beyond availability of translated materials, several design aspects can be improved upon. One area of need is in better communicating to parents both the purpose of the assessment and how assessment results will be used (see Goodman \& Hambleton, 2004; Kim et al., 2016; Roduta Roberts \& Gotch; 2019). Most states included the prior, but fewer academic achievement and ELP assessments included statements on intended use. This is especially important for ELP assessments as the results have high-stakes implications for students (e.g., whether they receive instructional support services). Echoing Kim et al. (2016), we argue that parents should be made aware of how such scores will impact their children, which may be important due to the unfamiliarity that many EL parents may have about the U.S. education system (e.g., Zapata et al., 2014).

Other layout recommendations, such as personalization in the body of the report (Goodman \& Hambleton, 2004) and directly linking to sample test items (Goodman \& Hambleton, 2004; NEGP, 1998), were mostly unavailable across assessment types. The latter was rated as a highly important and useful feature of score reports by EL parents (Kannan et al., 2018), but was rarely featured on score reports of any assessment type. Providing such information may be of assistance in giving parents a better idea of what their children are being assessed on and how they are being assessed.

Two areas of improvement are noted for the reporting of scores. First, few ELP score reports included norm-referenced information $(7 / 51 ; 13.7 \%)$, most likely, due to the difficulty in constructing meaningful norming groups for ELs given the diversity of this population. However, as prior research has shown that parents value norm-referenced information (Kannan et al., 2018; Zapata-Rivera et al., 2014), testing programs may look to identify solutions to providing such information. Second, as suggested by Kim et al. (2016), score reports should have 
a student score history, which we found to be rarely present across assessment types. Providing both types of information allows parents to see how their child: (a) has progressed over time in their academic content knowledge and ELP; and (b) where the child compares to other students in the school, district, and state. However, without such information, scores may be less meaningful to parents as the scores lack context. For example, a "proficient" score one year may indicate a negative trend if every previous year the student was "excelling".

\section{Recommendations for Practice}

Given these areas of improvement, we provide the following general recommendations that may contribute to the increased accessibility and interpretability in reporting assessment results to EL parents. In addition to these, we recognize the diversity that exists within and between states and recommend that each state agency conducts interviews or focus groups with parents to directly determine their specific needs.

- Linguistic Accessibility: To increase linguistic accessibility, we recommend the use of internet-based score reports in which Google translate can be embedded. Such a practice is currently utilized to great effect for parent websites, allowing accessibility to a broad variety of languages. ${ }^{11}$ Furthermore, we found that in some states the responsibility of translating score report materials is placed on local school districts. Such a practice may burden practitioners with limited knowledge of translation practices and financial resources. Thus, we would recommend score reporting should be coordinated at the state level rather than at the local level. For language populations that predominantly reside within one or two districts, state agencies might partner with translators from those districts. In doing so, smaller districts, or districts with much smaller populations in that language group, would

\footnotetext{
${ }^{11}$ Research on people's comprehension of Google translations has had mixed results depending on the context (Bahri \& Mahadi, 2016; Guo, 2016), so we recommend future research explore this tool specifically in this context.
} 
still have access to the translated materials. This would ensure that every state is meeting federal guidelines on language accessibility.

- Intended Use: Parents should know how scores are used to impact their children's learning. This is most important for ELP score reports, which have tangible personal stakes that parents should be aware of, and as a result, should be clearly stated on the score report. It is also recommended that states note potential score misuses. Such information would arm parents with knowledge to protect their children from unintended consequential decisions. In addition, score reports ought to provide a description of the skills required within each subdomain, beyond just the title of the subdomain - previous research has shown parents want to know this. One helpful way to do this is by including example items in the interpretive guide or providing a direct HTML link to these items in the score report.

- Test Performance: Most states do an excellent job of reporting normative information on state academic achievement score reports, but we suggest that states consider how this information could also be included on ELP score reports, so that parents can better contextualize their child's scores. Beyond providing a basis for gauging their children's learning, this information can also serve as an important indicator of school quality for parents, as it allows them to use their child's performance as a proxy for instructional effectiveness (A-Plus Communications, 1999). Similarly, a comparison of performance levels or scale scores to depict student progress between years should also be included to better assist parents in evaluating their child's performance. This is especially true on ELP score reports where personal stakes are higher. Lastly, in line with prior recommendations, score reports should provide measurement error graphically, with a description of those error bands either in the report or in the translated interpretive guide. 
- Statistical Jargon: In general, jargon usage was employed at a minimum, which is a trend that should continue going forward. That said, it ought not to be assumed that parents understand even basic statistical terms such as "mean" and "average", as not all parents understand such jargon (Zapata-Rivera et al., 2014); these terms should be summarized in the interpretive guide or the score report if utilized.

- Follow-up Information: First and foremost, we recommend that interpretive guides, and access to translated interpretive guides be (a) included with the score report or (b) linked to directly from the score report, so that parents may immediately access these materials if they have questions. With that in mind, we also encourage SEAs to include on both the score report and interpretive guide information on who to contact if parents have additional questions, follow-up activities parents can do with their children to help their scores improve, as well as a link to a website with parent resources available in different languages.

\section{Limitations and Future Research Directions}

The findings from this study should be interpreted in light of a number of limitations. To begin with, our analysis of score reporting practices was based on the analysis of resources made available via testing programs' websites. This required the assumption that all resources were both up-to-date and accessible to the general public. Web-based score reports, if they existed, were not typically made available to the general public; thus, our analysis is based on the static reports that states did provide. Although we made every effort to contact representatives of testing programs when information was not made publicly available, in some cases, we were unable to get a response. In instances in which information was available, we did not follow up with states to ensure its accuracy, so it is unclear whether such information was up-to-date. Therefore, the information collected may not be reflective of current score reporting practices for 
all testing programs sampled. In addition, much of the data collection and coding was conducted by one coder, so the final sample may reflect some amount of coder bias.

Additionally, a number of assumptions were made concerning parental accessibility of score reports. As an example, it was assumed that the availability of a native language translation would assist parents in better understanding their child's performance. Yet, such an assumption requires that parents can read in their native language, which may be untenable if parents did not receive formal education in their native language and/or speak a language in which the written form is not widespread (e.g., Hmong). In such circumstances, availability of a native language translation would not increase accessibility. Furthermore, it was assumed that native language score report materials would be helpful in increasing parents' interpretability without consideration for media platform delivery. However, accessibility of such information may be limited for foreign-born and nonnative English speakers if delivered electronically, as they have been shown to have less access to (and, when controlling for access, less use of) the Internet than native English speakers (Brown et al., 2016). Therefore, states should consider how to provide assessment result information using both electronic and non-electronic means to increase accessibility for this population.

Finally, our evaluation of score reporting and interpretive guide characteristics was based on prior literature that has recommended best practices primarily for native English-speaking parents (e.g., Goodman \& Hambleton, 2004). Given that audience analyses of score reporting practices have previously been conducted for other assessment stakeholders (Jaeger, 2003; Zapata-Rivera \& Katz, 2014), it is unclear whether such practices are effective for EL parents. The limited research that has investigated subpopulation differences in parental reporting preferences suggests that interpretability and comprehension may vary by education level 
(regardless of native language) and English language proficiency (e.g., Kannan et al., 2018).

Such results indicate the importance of score report designers considering parental heterogeneity. To do so requires further research to better understand: (a) if nonnative English speakers interpret score reports in the same way as their native English counterparts, after controlling for education level; and (b) if not, consider how linguistic accommodations (e.g., bilingual dictionary, rollover text description of terms) that go beyond translations can be built into score reporting systems to increase interpretability. However, what parents want to know may be at odds with the information they need for valid interpretation and use of assessment results, so future research should explore what score report information supports appropriate use of assessment results (Zapata-Rivera, vanWinkle and Zwick 2010, 2011). These lines of inquiry may provide fruitful recommendations for increasing score report accessibility for EL parents in the future. 


\section{References}

A-Plus Communications (1999). Reporting results: What the public wants to know. A companion report to Education Week's Quality counts '99. http://www.edcounts.org/archive/sreports/qc99/opinion/edweekresults.pdf.

Bahri, H., \& Mahadi, T. S. T. (2016). Google Translate as a supplementary tool for learning Malay: A case study at Universiti Sains Malaysia. Advances in Language and Literary Studies, 7(3), 161-167.

Barber, B. L., Paris, S. G., Evans, M., \& Gadsden, V. L. (1992). Policies for reporting test results to parents. Educational Measurement: Issues and Practice, 11(1), 15-20.

Bialik, K., Scheller, A., \& Walker, K. (2018, October 25). 6 facts about English language learners in U.S. public schools. Pew Research Center.

Brown, A., López, G., \& Lopez, M. G. (2016, July 20). Digital divide narrows for Latinos as more Spanish speakers and immigrants go online. Pew Research Center. https://www.pewresearch.org/hispanic/2016/07/20/digital-divide-narrows-for-latinos-asmore-spanish-speakers-and-immigrants-go-online/

Civil Rights Act of 1964, Pub.L. 88-352, 78 Stat. 241 (1964).

Education Week (2019, January 23). State grades on chance for success: 2020 map and rankings. https://www.edweek.org/leadership/state-grades-on-chance-for-success-2020map-and-rankings

Every Student Succeeds Act, 20 U.S.C. $§ 6311$ (2015). https://www.congress.gov/bill/114thcongress/senate-bill/1177

Faulkner-Bond, M., Shin, M., Wang, X., Zenisky, A. L., \& Moyer, E. (2013, April 28-30). Score reports for English proficiency assessments: Current practices and future directions. Paper presented at the annual conference of the National Council on Measurement in 
Education, San Francisco, CA.

Gamer, M., Lemon, J., \& Puspendra Singh, I. (2012) irr: Various Coefficients of Interrater Reliability and Agreement (Version 0.84.1) [Computer software].

Goodman, D. P., \& Hambleton, R. K. (2004). Student test score reports and interpretive guides: Review of current practices and suggestions for future research. Applied Measurement in Education, 17(2), 145-220.

Guo, J. W. (2016). Is Google Translate adequate for facilitating instrument translation from English to Mandarin? CIN: Computers, Informatics, Nursing, 34(9), 377-383.

Hambleton, R. K., \& Zenisky, A. L. (2013). Reporting test scores in more meaningful ways: A research-based approach to score report design. In K. F. Geisinger, B. A. Bracken, J. F. Carlson, J.-I. C. Hansen, N. R. Kuncel, S. P. Reise, \& M. C. Rodriguez (Eds.), Testing and Assessment in School Psychology and Education (p. 479-494). American Psychological Association.

Jaeger, R. M. (2003). NAEP validity studies: Reporting the results of the National Assessment of Educational Progress. NCES.

Kannan, P., Zapata-Rivera, D., \& Leibowitz, E. A. (2018). Interpretation of score reports by diverse subgroups of parents. Educational Assessment, 23(3), 173-194.

Kim, A. A., Kondo, A., Blair, A., Mancilla, L., Chapman, M., \& Wilmes, C. (2016). Interpretation and use of K-12 language proficiency assessment score reports: Perspectives of educators and parents. WIDA.

Landis, J. R., \& Koch, G. G. (1977). The measurement of observer agreement for categorical data. Biometrics, 33, 159-174.

McQuiggan, M., Megra, M., \& Grady, S. (2017). Parent and family involvement in education: 
Results from the national household surveys program of 2016. Institute of Education Sciences.

Miller, J. A., \& Watkins, M. W. (2010). The use of graphs to communicate psychoeducational test results to parents. Journal of Applied School Psychology, 26(1), 1-16.

National Center for Education Statistics (2020). English language learners in public schools. https://nces.ed.gov/programs/coe/indicator_cgf.asp

National Education Goals Panel (1998). Talking about tests: An idea book for state leaders. U.S. Government Printing Office.

Roduta Roberts, M., \& Gotch, C. M. (2019). Development and examination of a tool to assess score report quality. Frontiers in Education, 4, 1-10.

https://doi.org/10.3389/feduc.2019.00020

Sanchez, C. (2017, February 23). English language learners: How your state is doing. nprED. https:/www.npr.org/sections/ed/2017/02/23/512451228/5-million-english-languagelearners-a-vast-pool-of-talent-at-risk

U.S. Census Bureau (2015, November 3). Census bureau reports at least 350 languages spoken in U.S. homes. https://www.census.gov/newsroom/press-releases/2015/cb15-185.html

U.S. Department of Education (n.d.). Our nation's English learners: What are their characteristics? https://www2.ed.gov/datastory/el-characteristics/index.html

Zapata-Rivera, D., \& Katz, I. R. (2014). Keeping your audience in mind: Applying audience analysis to the design of interactive score reports. Assessment in Education: Principles, Policy \& Practice, 21(4), 442-463.

Zapata-Rivera, D., vanWinkle, W., \& Zwick, R. (2010, May 1-3). Exploring effective communication and appropriate use of assessment results through teacher score reports. 
Paper presented at the annual conference of the National Council on Measurement in Education, Denver, CO.

Zapata-Rivera, D., vanWinkle, W., \& Zwick, R. (2011, April 8-12). Exploring teachers' understanding and use of assessment results. Paper presented at the annual conference of the American Educational Research Association, New Orleans, LA.

Zapata-Rivera, D., Vezzu, M., Nabors-Oláh, L., Leusner, D., Biggers, K., \& Bertling, M. (2014, April 3-7). Designing and evaluating score reports for parents who are English learners. Paper presented at the annual conference of the American Educational Research Association, Philadelphia, PA.

Zenisky, A. L., \& Hambleton, R. K. (2012). Developing test score reports that work: The process and best practices for effective communication. Educational Measurement: Issues and Practice, 31(2), 21-26.

Zuckerman, M. A. (2010). When English-only meets voting rights. Yale Law \& Policy Review, Inc., 28(2), 353-377. 
Table 1

Presence of Score Report and Interpretive Guide Documents by State

\begin{tabular}{|c|c|c|c|c|c|c|c|c|}
\hline State & $\begin{array}{c}\text { Academic Achievement } \\
\text { Report }^{\mathrm{B}}\end{array}$ & $\begin{array}{c}\text { Translated }^{\mathrm{C}} \\
\text { Academic } \\
\text { Achievement }^{\mathrm{A}} \\
\text { Report }^{\mathrm{B}}\end{array}$ & $\begin{array}{c}\text { Academic } \\
\text { Achievement }^{\mathrm{A}} \\
\text { Interpretive Guide }^{\mathrm{D}}\end{array}$ & $\begin{array}{c}\text { Translated }^{\mathrm{C}} \text { Academic }^{\mathrm{A}} \\
\text { Achievement }^{\mathrm{A}} \\
\text { Interpretive Guide }^{\mathrm{D}}\end{array}$ & $\begin{array}{c}\text { ELP }^{\mathrm{E}} \\
\text { Report }^{\mathrm{B}}\end{array}$ & $\begin{array}{c}\text { Translated } \\
\text { ELP }^{\mathrm{C}} \text { Report }^{\mathrm{B}}\end{array}$ & $\begin{array}{c}\text { ELP }^{\mathrm{E}} \\
\text { Interpretive } \\
\text { Guide }^{\mathrm{D}}\end{array}$ & $\begin{array}{l}\text { Translated }^{\mathrm{C}} \mathrm{ELP}^{\mathrm{E}} \\
\text { Interpretive Guide }\end{array}$ \\
\hline Alabama & $\mathrm{N}^{1}$ & NA & $\mathrm{N}^{1}$ & NA & $\mathrm{Y}$ & $\mathrm{Y}$ & $\mathrm{Y}$ & $\mathrm{Y}$ \\
\hline Alaska & $\mathrm{Y}^{2}$ & $\mathrm{~N}$ & $\mathrm{Y}$ & $\mathrm{N}$ & $\mathrm{Y}$ & $\mathrm{Y}$ & $\mathrm{Y}$ & $\mathrm{Y}$ \\
\hline Arizona & $\mathrm{Y}$ & $\mathrm{Y}$ & $\mathrm{N}$ & NA & $\mathrm{Y}^{2}$ & $\mathrm{Y}$ & $\mathrm{Y}$ & $\mathrm{N}$ \\
\hline Arkansas & $\mathrm{Y}$ & $\mathrm{N}$ & $\mathrm{Y}$ & $\mathrm{Y}$ & $\mathrm{Y}$ & $\mathrm{Y}$ & $\mathrm{Y}$ & $\mathrm{N}$ \\
\hline California & $\mathrm{Y}$ & $\mathrm{Y}$ & $\mathrm{Y}$ & $\mathrm{Y}$ & $\mathrm{Y}$ & $\mathrm{Y}$ & $\mathrm{Y}$ & $\mathrm{Y}$ \\
\hline Colorado & $\mathrm{Y}$ & $\mathrm{Y}$ & $\mathrm{Y}$ & $\mathrm{Y}$ & $\mathrm{Y}$ & $\mathrm{Y}$ & $\mathrm{Y}$ & $\mathrm{Y}$ \\
\hline Connecticut & $\mathrm{Y}$ & $\mathrm{Y}$ & $\mathrm{Y}$ & $\mathrm{N}$ & $\mathrm{Y}$ & $\mathrm{Y}$ & $\mathrm{N}$ & NA \\
\hline Delaware & $\mathrm{Y}$ & $\mathrm{Y}$ & $\mathrm{Y}$ & $\mathrm{Y}$ & $\mathrm{Y}$ & $\mathrm{Y}$ & $\mathrm{Y}$ & $\mathrm{Y}$ \\
\hline Washington D.C. & $\mathrm{Y}$ & $\mathrm{Y}$ & $\mathrm{Y}$ & $\mathrm{N}$ & $\mathrm{Y}$ & $\mathrm{Y}$ & $\mathrm{Y}$ & $\mathrm{Y}$ \\
\hline Florida & $\mathrm{Y}$ & $\mathrm{Y}$ & $\mathrm{Y}$ & $\mathrm{N}$ & $\mathrm{Y}$ & $\mathrm{Y}$ & $\mathrm{Y}$ & $\mathrm{Y}$ \\
\hline Georgia & $\mathrm{Y}$ & $\mathrm{Y}$ & $\mathrm{Y}$ & $\mathrm{Y}$ & $\mathrm{Y}$ & $\mathrm{Y}$ & $\mathrm{Y}$ & $\mathrm{Y}$ \\
\hline Hawaii & $\mathrm{Y}$ & $\mathrm{N}$ & $\mathrm{Y}$ & $\mathrm{N}$ & $\mathrm{Y}$ & $\mathrm{Y}$ & $\mathrm{Y}$ & $\mathrm{Y}$ \\
\hline Idaho & $\mathrm{Y}$ & $\mathrm{Y}$ & $\mathrm{Y}$ & $\mathrm{Y}$ & $\mathrm{Y}$ & $\mathrm{Y}$ & $\mathrm{Y}$ & $\mathrm{Y}$ \\
\hline Illinois & $\mathrm{Y}$ & $\mathrm{Y}$ & $\mathrm{Y}$ & $\mathrm{Y}$ & $\mathrm{Y}$ & $\mathrm{Y}$ & $\mathrm{Y}$ & $\mathrm{Y}$ \\
\hline Indiana & $\mathrm{Y}$ & $\mathrm{Y}$ & $\mathrm{Y}^{3}$ & $\mathrm{Y}$ & $\mathrm{Y}$ & $\mathrm{Y}$ & $\mathrm{Y}$ & $\mathrm{Y}$ \\
\hline Iowa & $\mathrm{Y}$ & $\mathrm{Y}$ & $\mathrm{Y}$ & $\mathrm{Y}$ & $\mathrm{Y}$ & $\mathrm{Y}$ & $\mathrm{Y}$ & $\mathrm{N}$ \\
\hline Kansas & $\mathrm{Y}$ & $\mathrm{N}$ & $\mathrm{Y}$ & $\mathrm{Y}$ & $\mathrm{Y}^{2}$ & $\mathrm{Y}$ & $\mathrm{Y}$ & $\mathrm{Y}$ \\
\hline Kentucky & $\mathrm{Y}$ & $\mathrm{N}$ & $\mathrm{N}$ & NA & $\mathrm{Y}$ & $\mathrm{Y}$ & $\mathrm{Y}$ & $\mathrm{Y}$ \\
\hline Louisiana & $\mathrm{Y}$ & $\mathrm{Y}$ & $\mathrm{Y}$ & $\mathrm{Y}$ & $\mathrm{Y}$ & $\mathrm{Y}$ & $\mathrm{Y}$ & $\mathrm{Y}$ \\
\hline Maine & $\mathrm{Y}^{2}$ & $\mathrm{~N}$ & $\mathrm{Y}$ & $\mathrm{N}$ & $\mathrm{Y}$ & $\mathrm{Y}$ & $\mathrm{Y}$ & $\mathrm{Y}$ \\
\hline Maryland & $\mathrm{Y}^{2}$ & $\mathrm{Y}$ & $\mathrm{Y}$ & $\mathrm{Y}$ & $\mathrm{Y}$ & $\mathrm{Y}$ & $\mathrm{Y}$ & $\mathrm{Y}$ \\
\hline Massachusetts & $\mathrm{Y}$ & $\mathrm{Y}$ & $\mathrm{Y}$ & $\mathrm{N}$ & $\mathrm{Y}$ & $\mathrm{Y}$ & $\mathrm{Y}$ & $\mathrm{Y}$ \\
\hline Michigan & $\mathrm{Y}$ & $\mathrm{N}$ & $\mathrm{Y}$ & $\mathrm{N}$ & $\mathrm{Y}$ & $\mathrm{Y}$ & $\mathrm{Y}$ & $\mathrm{Y}$ \\
\hline Minnesota & $\mathrm{Y}$ & $\mathrm{N}$ & $\mathrm{Y}$ & $\mathrm{Y}$ & $\mathrm{Y}$ & $\mathrm{Y}$ & $\mathrm{Y}$ & $\mathrm{Y}$ \\
\hline Mississippi & $\mathrm{Y}$ & $\mathrm{N}$ & $\mathrm{Y}$ & $\mathrm{N}$ & $\mathrm{Y}$ & $\mathrm{Y}$ & $\mathrm{N}$ & NA \\
\hline Missouri & $\mathrm{Y}$ & $\mathrm{N}$ & $\mathrm{Y}$ & $\mathrm{N}$ & $\mathrm{Y}$ & $\mathrm{Y}$ & $\mathrm{Y}$ & $\mathrm{Y}$ \\
\hline Montana & $\mathrm{Y}$ & $\mathrm{N}$ & $\mathrm{Y}$ & $\mathrm{Y}$ & $\mathrm{Y}$ & $\mathrm{Y}$ & $\mathrm{Y}$ & $\mathrm{Y}$ \\
\hline Nebraska & $\mathrm{Y}$ & $\mathrm{Y}$ & $\mathrm{Y}$ & $\mathrm{Y}$ & $\mathrm{Y}$ & $\mathrm{Y}$ & $\mathrm{Y}$ & $\mathrm{N}$ \\
\hline Nevada & $\mathrm{Y}$ & $\mathrm{Y}$ & $\mathrm{Y}$ & $\mathrm{Y}$ & $\mathrm{Y}$ & $\mathrm{Y}$ & $\mathrm{Y}$ & $\mathrm{Y}$ \\
\hline New Hampshire & $\mathrm{Y}^{2}$ & $\mathrm{~N}$ & $\mathrm{Y}$ & $\mathrm{N}$ & $\mathrm{Y}$ & $\mathrm{Y}$ & $\mathrm{Y}$ & $\mathrm{Y}$ \\
\hline New Jersey & $\mathrm{Y}$ & $\mathrm{Y}$ & $\mathrm{Y}$ & $\mathrm{Y}$ & $\mathrm{Y}$ & $\mathrm{Y}$ & $\mathrm{Y}$ & $\mathrm{Y}$ \\
\hline New Mexico & $\mathrm{Y}$ & $\mathrm{N}$ & $\mathrm{Y}^{3}$ & $\mathrm{~N}$ & $\mathrm{Y}$ & $\mathrm{Y}$ & $\mathrm{Y}$ & $\mathrm{Y}$ \\
\hline New York & $\mathrm{Y}$ & $\mathrm{Y}$ & $\mathrm{Y}$ & $\mathrm{N}$ & $\mathrm{Y}$ & $\mathrm{Y}$ & $\mathrm{Y}$ & $\mathrm{Y}$ \\
\hline North Carolina & $\mathrm{Y}$ & $\mathrm{Y}$ & $\mathrm{Y}$ & $\mathrm{Y}$ & $\mathrm{Y}$ & $\mathrm{Y}$ & $\mathrm{Y}$ & $\mathrm{Y}$ \\
\hline North Dakota & $\mathrm{Y}$ & $\mathrm{N}$ & $\mathrm{Y}$ & $\mathrm{N}$ & $\mathrm{Y}$ & $\mathrm{Y}$ & $\mathrm{Y}$ & $\mathrm{Y}$ \\
\hline Ohio & $\mathrm{Y}^{2}$ & $\mathrm{~N}$ & $\mathrm{Y}$ & $\mathrm{Y}$ & $\mathrm{Y}$ & $\mathrm{Y}$ & $\mathrm{Y}$ & $\mathrm{N}$ \\
\hline Oklahoma & $\mathrm{Y}$ & $\mathrm{Y}$ & $\mathrm{Y}$ & $\mathrm{Y}$ & $\mathrm{Y}$ & $\mathrm{Y}$ & $\mathrm{Y}$ & $\mathrm{Y}$ \\
\hline Oregon & $\mathrm{Y}$ & $\mathrm{Y}$ & $\mathrm{Y}$ & $\mathrm{Y}$ & $\mathrm{Y}$ & $\mathrm{Y}$ & $\mathrm{Y}$ & $\mathrm{N}$ \\
\hline Pennsylvania & $\mathrm{Y}$ & $\mathrm{N}$ & $\mathrm{Y}$ & $\mathrm{Y}$ & $\mathrm{Y}$ & $\mathrm{Y}$ & $\mathrm{Y}$ & $\mathrm{Y}$ \\
\hline Rhode Island & $\mathrm{Y}$ & $\mathrm{Y}$ & $\mathrm{Y}$ & $\mathrm{N}$ & $\mathrm{Y}$ & $\mathrm{Y}$ & $\mathrm{Y}$ & $\mathrm{Y}$ \\
\hline South Carolina & $\mathrm{Y}$ & $\mathrm{Y}$ & $\mathrm{Y}$ & $\mathrm{N}$ & $\mathrm{Y}$ & $\mathrm{Y}$ & $\mathrm{Y}$ & $\mathrm{Y}$ \\
\hline South Dakota & $\mathrm{Y}$ & $\mathrm{Y}$ & $\mathrm{Y}$ & $\mathrm{Y}$ & $\mathrm{Y}$ & $\mathrm{Y}$ & $\mathrm{Y}$ & $\mathrm{Y}$ \\
\hline Tennessee & $\mathrm{Y}$ & $\mathrm{N}$ & $\mathrm{Y}$ & $\mathrm{Y}$ & $\mathrm{Y}$ & $\mathrm{Y}$ & $\mathrm{Y}$ & $\mathrm{Y}$ \\
\hline Texas & $\mathrm{Y}$ & $\mathrm{Y}$ & $\mathrm{Y}$ & $\mathrm{Y}$ & $\mathrm{Y}$ & $\mathrm{Y}$ & $\mathrm{Y}$ & $\mathrm{Y}$ \\
\hline Utah & $\mathrm{Y}^{2}$ & $\mathrm{~N}$ & $\mathrm{Y}$ & $\mathrm{N}$ & $\mathrm{Y}$ & $\mathrm{Y}$ & $\mathrm{Y}$ & $\mathrm{Y}$ \\
\hline Vermont & $\mathrm{Y}$ & $\mathrm{N}$ & $\mathrm{Y}$ & $\mathrm{N}$ & $\mathrm{Y}$ & $\mathrm{Y}$ & $\mathrm{Y}$ & $\mathrm{Y}$ \\
\hline Virginia & $\mathrm{Y}$ & $\mathrm{N}$ & $\mathrm{N}$ & NA & $\mathrm{Y}$ & $\mathrm{Y}$ & $\mathrm{Y}$ & $\mathrm{Y}$ \\
\hline Washington & $\mathrm{Y}$ & $\mathrm{N}$ & $\mathrm{Y}$ & $\mathrm{Y}$ & $\mathrm{Y}$ & $\mathrm{Y}$ & $\mathrm{Y}$ & $\mathrm{N}$ \\
\hline West Virginia & $\mathrm{Y}^{2}$ & $\mathrm{Y}$ & $\mathrm{Y}$ & $\mathrm{N}$ & $\mathrm{Y}$ & $\mathrm{Y}$ & $\mathrm{Y}$ & $\mathrm{N}$ \\
\hline Wisconsin & $\mathrm{Y}$ & $\mathrm{Y}$ & $\mathrm{Y}$ & $\mathrm{Y}$ & $\mathrm{Y}$ & $\mathrm{Y}$ & $\mathrm{Y}$ & $\mathrm{Y}$ \\
\hline Wyoming & $\mathrm{Y}^{2}$ & $\mathrm{Y}$ & $\mathrm{Y}$ & $\mathrm{Y}$ & $\mathrm{Y}$ & $\mathrm{Y}$ & $\mathrm{Y}$ & $\mathrm{Y}$ \\
\hline
\end{tabular}

"Academic Achievement" refers to large-scale statewide academic achievement assessments

B "Report" refers to the score report associated with the specified assessment

${ }^{\mathrm{C}}$ For both score reports and interpretive guides, "translated" indicates that all linguistic components of a score report or interpretive guide were presented in more than one language.

D "Interpretive Guide" refers to additional supplemental documents provided with the score report to aid in its comprehension

E "ELP" refers to English Learner Proficiency assessments such as WIDA

${ }^{1}$ State was in process of developing new score reports and could not provide a copy

${ }^{2}$ No access to score report, but interpretive guide has example score report embedded

${ }^{3}$ Interpretive guide information for this state was embedded in the score report 


\section{Appendix A}

\section{Example E-mail to a State Education Agency}

Hello [Assessment Director],

I am a PhD student at the University of Minnesota working on a research project with my advisor Dr. Joseph Rios in which we analyze trends in score reporting across the United States. I couldn't find these on your website, so I was wondering if you might send me the following documents:

- An example of the [Assessment Name] score report that would be sent home to parents

- Any interpretive materials that would get sent to parents to aid in comprehension of the score report

Thank you for taking the time to help our research!

Sam 